Review Article

\title{
Advanced Glycation End Products: Potential Mechanism and Therapeutic Target in Cardiovascular Complications under Diabetes
}

\author{
Ping Yang, Jian Feng, Qing Peng, Xing Liu, and Zhongcai Fan $(\mathbb{D}$ \\ Department of Vasculocardiology, The Affiliated Hospital of Southwest Medical University, Luzhou, Sichuan 646000, China \\ Correspondence should be addressed to Zhongcai Fan; zhongcaifan1982@swmu.edu.cn
}

Received 19 July 2019; Accepted 25 November 2019; Published 6 December 2019

Guest Editor: Maria Luca

Copyright (c) 2019 Ping Yang et al. This is an open access article distributed under the Creative Commons Attribution License, which permits unrestricted use, distribution, and reproduction in any medium, provided the original work is properly cited.

\begin{abstract}
The occurrence and development of cardiovascular complications are predominantly responsible for the increased morbidity and mortality observed in patients with diabetes. Oxidative stress under hyperglycemia is currently considered the initial link to diabetic cardiovascular complications and a key node for the prevention and treatment of diabetes-related fatal cardiovascular events. Numerous studies have indicated that the common upstream pathway in the context of oxidative stress in the cardiovascular system under diabetic conditions is the interaction of advanced glycation end products (AGEs) with their receptors (RAGEs). Therefore, a further understanding of the relationship between oxidative stress and AGEs is of great significance for the prevention and treatment of cardiovascular complications in patients with diabetes. In this review, we will briefly summarize the recent research advances in diabetes with an emphasis on oxidative stress and its association with AGEs in diabetic cardiovascular complications.
\end{abstract}

\section{Introduction}

Diabetes and its associated complications present a global burden in terms of human health and economics [1], of which the prevalence is rising at an exponential rate worldwide. According to data from the International Diabetes Federation (IDF), the currently estimated total number of 18- to 99-year-old diabetic patients is approximately 425 million globally. Moreover, the number of adult diabetes patients is expected to continue to increase over the next several decades due to aging, urbanization, and changes in diet and physical activity. The number of adult diabetes patients was expected to increase to 693 million by 2045 $[2,3]$. Hyperglycemia and insulin resistance can affect various tissues and organs throughout the body, causing chronic complications of multiple systems and organs, especially the cardiovascular system $[4,5]$. Pathological remodeling of the heart is characterized by left ventricular concentric hypertrophy and perivascular and interstitial fibrosis, leading to diastolic dysfunctions [6]. Diabetic macroangiopathy includes atherosclerosis of the aorta, coronary arteries, cerebral arteries, renal arteries, and peripheral arteries, while diabetic microangiopathy includes diabetic retinopathy and diabetic nephropathy $[7,8]$.

Both macro- and microvascular complications adversely affect the quality of life of patients with diabetes $[9,10]$. The death risk from major adverse cardiovascular events in diabetic patients is higher than that in nondiabetic patients. Cardiovascular disease is more severe and extensive in the former than in the latter, with a worse prognosis and earlier onset. Patients with type 2 diabetes are 2-4 times more likely to develop heart failure than nondiabetic patients [11]. Approximately $70-80 \%$ of diabetes patients eventually die from cardiovascular complications [12]. Moreover, approximately $3 / 4$ patients with type 2 diabetes have a variety of cardiovascular risk factors, such as hypertension, dyslipidemia, and obesity. The clusters of these risk factors can directly promote the occurrence of cardiovascular complications in diabetes [13].

Although diabetes treatment has undergone a transformation from simple control of hyperglycemia to multi-risk-factor management, the prevention and control of cardiovascular 
complications in this population still remain challenging. Sustained blood-glucose elevation is the initiating factor in the pathogenesis of diabetic cardiovascular complications. However, the mechanisms by which hyperglycemia can affect the cardiovascular system have not been adequately addressed.

Various hyperglycemia-elicited metabolic and hemodynamic derangements have been proposed to contribute to cardiovascular complications in diabetes [6]. The currently identified mechanisms include increased oxidative stress $[14,15]$, activation of protein kinase C (PKC) [16], chronic inflammation [17, 18], mitochondrial dysfunction [19], and activation of the renin-angiotensin system (RAS) [20]. Among these, increased oxidative stress is considered to be the initial core mechanism leading to diabetic cardiovascular diseases [21]. Therefore, understanding how oxidative stress is controlled in the context of cardiovascular complications is helpful for developing effective therapeutics against diabetes.

Advanced glycation end products (AGEs) are a general term for a class of heterogeneous compounds mainly derived from nonenzymatic saccharification (Maillard reactions) of reducing sugar on proteins, lipids, and nucleic acids. AGEs can increase the production of reactive oxygen species (ROS), thereby initiating intracellular oxidative stress [22]. Conversely, the increase in ROS production can in turn promote the production of AGEs, thereby forming a vicious circle between oxidative stress and AGEs. In this review, we will briefly summarize the recent research advances in in vitro and in vivo model systems of diabetes with an emphasis on oxidative stress and its association with AGEs in cardiovascular complications under diabetic conditions in an effort to provide some evidence for potential cardiometabolictargeted therapies for diabetes.

\section{Oxidative Stress}

Oxidative stress is defined as an imbalance between oxidization and antioxidation, which subsequently leads to multiple negative effects on cellular metabolism. "ROS" is a general term for active substances composed of oxygen in the body or in the natural environment, including free radicals (hydroxyl, superoxide) and nonradicals (hydrogen peroxide, singlet oxygen molecules). They are continuously generated and eliminated during redox reactions in life activities. ROS generation mainly stems from nicotinamide adenine dinucleotide phosphate (NADPH) oxidase [23]. Other sources include xanthine oxidase (XO) and nitric oxide synthase (NOS) decoupling.

Normally, a proper amount of ROS as a signaling molecule is indispensable for regulation of transcription factors, expression of apoptosis genes, and antibacterial and antiinflammatory effects. During pathological conditions, however, when the ROS level exceeds the buffering capacity of antioxidant enzymes and antioxidants, the balance between oxidation and antioxidation shifts the trend to oxidization, resulting in oxidative stress [24]. It has been reported that increased ROS levels can stimulate mitogen-activated protein kinase (MAPK), tyrosine kinase, Rho kinase, and transcrip- tion factor (NF- $\kappa \mathrm{B}, \mathrm{AP}-1$, and HIF-1) activation [25-27]. Furthermore, ROS can inactivate protein tyrosine phosphatase (PTP), increase the intracellular free calcium ion concentration, and modulate the expression and activation of proinflammatory genes [28]. Changes in these intracellular signals can lead to endothelial dysfunction and myocardial remodeling.

\section{Oxidative Stress in Diabetic Cardiovascular Complications}

Increased oxidative stress is considered the initial core mechanism leading to diabetic cardiovascular diseases [21, 22]. In diabetic cardiovascular complications, NADPH oxidase is activated under conditions of hyperglycemia [29], catalyzing the formation of superoxide anions, and the superoxide anion undergoes a series of reactions to convert to hydroxyl groups, resulting in excessive ROS synthesis and subsequently leading to oxidative stress. In addition, the antioxidant capacity of the defense system, including enzymatic antioxidants (superoxide dismutase), nonenzymatic antioxidants (vitamin C, coenzyme Q10), and metal complexes (copperbinding proteins), is decreased by hyperglycemia [30, 31]. Oxidative stress triggers inflammation, endothelial dysfunction, cardiomyocyte hypertrophy and apoptosis, and myocardial fibrosis, which subsequently lead to decreasing left ventricular compliance, diastolic dysfunction, and finally heart failure, arrhythmia, and/or even sudden cardiac death.

3.1. Oxidative Stress and Inflammation. As previously reported, oxidative stress and inflammation interact with each other to promote diabetic cardiovascular complications [32]. ROS directly or indirectly activate NF- $\kappa \mathrm{B}$, transforming growth factor- $\beta$ (TGF- $\beta$ ), MAPK, protein kinase $\mathrm{C}(\mathrm{PKC})$, stress-activated protein kinase, etc. They thereby trigger inflammation and myocardial fibrosis in the cardiovascular system in diabetes $[33,34]$. The expression of inflammatory factors such as tumor necrosis factor- $\alpha$ (TNF- $\alpha$ ) and interleukin-6 (IL-6) was demonstrated to promote cardiac fibroblast proliferation, thereby increasing collagen synthesis and ultimately leading to myocardial fibrosis [35]. Inflammatory factors are in turn considered to increase ROS [36]. NF- $\kappa \mathrm{B}$ can increase the expression of inducible nitric oxide synthase (iNOS), which promotes the generation of nitric oxide. Excessive nitric oxide and peroxyl radicals react to form peroxynitrate, which subsequently increases mitochondrial permeability and ROS production.

3.2. Oxidative Stress and Endothelial Cell Dysfunction. In addition, the sustained elevation of blood glucose can cause endothelial cell dysfunction [37, 38]. Accumulated superoxide and nitric oxide interact rapidly to form a highly active intermediate, peroxynitrite. Peroxynitrite is a strong cytotoxic oxidant that can cause nitrosylation, nitration, and oxidative damage of biomolecules such as proteins, lipids, and DNA in endothelial cells $[39,40]$. Simultaneously, peroxynitrite can cause the unfolding of endothelial NOS to form superoxide, and superoxide can continue to react with nitric oxide to form peroxynitrite, forming a vicious circle [41]. 


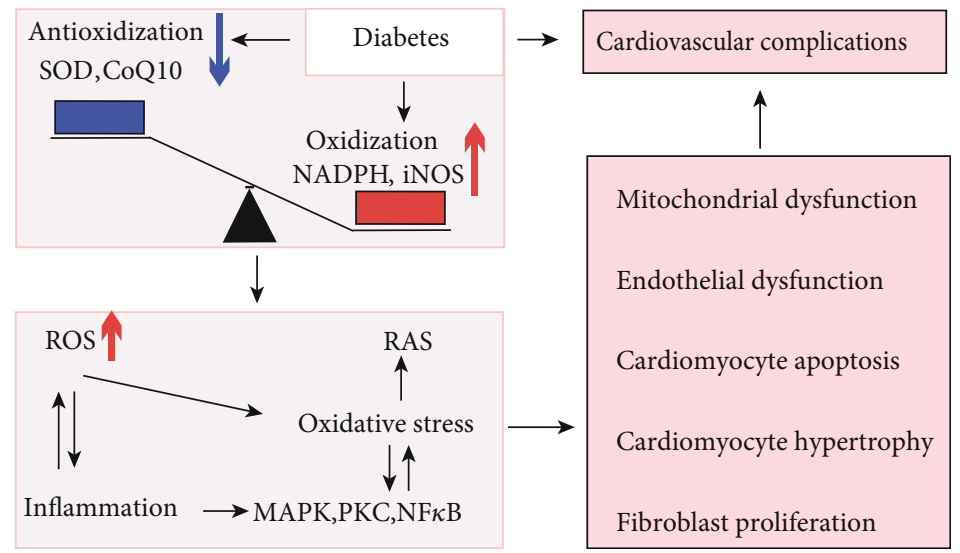

FIGURE 1: Oxidative stress plays an important role in diabetic cardiovascular complications. An impaired balance between oxidization and antioxidant activity in the diabetic cardiovascular system results in more pronounced ROS generation and oxidative stress. Oxidative stress interacts with inflammation and neurohumoral mechanisms, thereby promoting mitochondrial dysfunction, endothelial dysfunction, cardiac fibrosis, and hypertrophy.

3.3. Oxidative Stress and Cardiac Hypertrophy. Oxidative stress also plays a key role in promoting cardiac hypertrophy in diabetes $[42,43]$. Under the condition of hyperglycemia, ROS activate neurohumoral mechanisms such as the reninangiotensin-aldosterone system, endothelin-1, and the sympathetic nervous system $[44,45]$. Excessive activation of the renin-angiotensin-aldosterone system can induce cardiac hypertrophy and abnormal cardiac functions [46]. Studies have shown that the angiotensin-converting enzyme inhibitor lisinopril can inhibit 8-hydroxydeoxyguanosine and hydroxyl radicals in cardiomyocytes in diabetic rats and thus alleviate cardiac inflammation, fibrosis, and hypertrophy [47].

3.4. Oxidative Stress and Mitochondrial Dysfunction. Moreover, ROS-mediated activation of mitochondrial uncoupling proteins, increased proton leakage, and oxidative phosphorylation uncoupling can result in reduced adenosine triphosphate (ATP) production, thereby inducing cardiomyocyte apoptosis $[48,49]$. The oxidative phosphorylation respiratory chain enzyme complex is composed of mitochondrial DNA and nuclear DNA-encoding subunits involved in the oxidative phosphorylation of mitochondria $[50,51]$. On the one hand, increased ROS can directly damage mitochondrial DNA and membranes [52]. In addition to changes in mitochondrial ATP production, abnormalities in mitochondrialsurface membrane ion channels and sarcomere-associated proteins can also cause cardiac dysfunction [53]. The calcium signaling pathway is a prerequisite for myocardial cell contraction and relaxation. The sarcoplasmic calcium pump is an important component of the calcium signaling pathway, which relaxes cardiomyocytes by isolating calcium ions. ROS can cause dysfunction of the sarcoplasmic reticulum, leading to the accumulation of calcium ions in the cells, followed by cardiac dysfunction, arrhythmia, and heart failure [54].

All the above studies have shown that oxidative stress in the heart can cause endothelial and myocardial metabolic abnormalities through inflammation, mitochondrial damage, glucose metabolism disorders, and other mechanisms, eventually leading to myocardial contractile and diastolic dysfunction or even heart failure. Moreover, the abnormal elevation of oxidative stress can further cause glucose metabolism disorders, thereby creating a vicious circle if not controlled (Figure 1).

\section{AGE Metabolism in Diabetic Cardiovascular Complications}

The nonenzymatic glycosylation reaction, also known as the Maillard reaction, was proposed by Maillard in the early $20^{\text {th }}$ century [55]. AGEs are highly heterogeneous and exist in many different forms in vivo. Typical AGEs include pentosidine, carboxymethyl lysine (CML), carboxyethyl lysine (CEL), pyralline (Pyr), argpyrimidine (ArgP), and crosslinked AGEs $[56,57]$. Once synthesis is finished, AGEs can accumulate with aging and can be used as a biomarker of aging [58]. AGEs function mainly through binding to specific receptors [59]. Currently identified receptors for AGEs include RAGE, macrophage scavenger receptors type I and type II, oligosaccharyl transferase-48, 80K-H phosphoprotein, and galectin-3, among which, RAGE is the major one [60]. The downstream targets of RAGE include NADPH oxidase, MAPK, extracellular signal-regulated kinase 1/2 (ERK1/2) and p38-mediated signaling pathways, and ultimately NF- $\kappa \mathrm{B}[61,62]$.

Generally, the Maillard reaction occurs in some slowerrenewing proteins, such as type IV collagen, laminin, and elastin, and the rate of AGE generation is relatively slow [63]. However, the formation and accumulation of AGEs have been known to progress at an accelerated rate in diabetes [64]. On the one hand, sustained hyperglycemia causes more rapid nonenzymatic glycosylation of the abovementioned proteins and results in the increase in AGEs. On the other hand, AGEs are scarcely degraded and remain for a long time in tissues even if glycemic control is improved [65]. The clearance of AGEs is mediated by specific receptors 


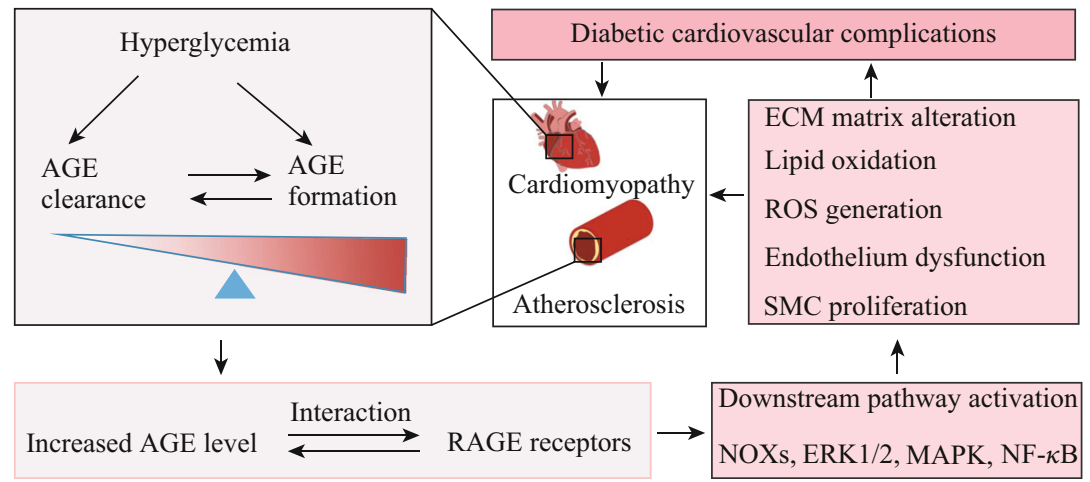

FIGURE 2: AGEs play an important role in diabetic cardiovascular complications. Under the condition of hyperglycemia, the balance between AGE formation and clearance is impaired in the diabetic cardiovascular system which thereby result in increased AGEs. AGEs interact with AGE receptors and then promote diabetic cardiovascular complications.

on macrophages via internalization or by extracellular proteolytic systems that decompose them into relatively lower molecular weight AGEs, which are finally cleared by the kidneys [66]. When nephritic insufficiency occurs in diabetes, AGEs increase in the circulation and further aggravate renal dysfunction [67]. Therefore, previous studies have paid more attention to the relationship between AGEs and diabetic nephropathy. Studies have confirmed that plasma AGE levels are closely related to the development of diabetic glomerular sclerosis, tubulointerstitial fibrosis, and mesangial cell proliferation $[68,69]$.

Increasing evidence indicates that AGEs are also involved in the occurrence and development of cardiovascular diseases. The increase in plasma AGEs is more pronounced in diabetic patients with coronary heart disease than in patients without coronary heart disease. Nin et al. [70] confirmed that plasma AGE levels are associated with all-cause mortality in fatal or nonfatal coronary artery disease. Steine et al. and Berg et al. [71, 72] found that left ventricular dysfunction in patients with type 1 diabetes is associated with plasma AGE levels. Jia et al. [73] also found that the level of tissue AGEs was independently associated with cardiac systolic dysfunction in diabetic patients with heart failure compared with diabetic patients without heart failure. Spadaccio and colleagues [74] showed that the risk of restenosis in diabetic patients with high plasma AGEs who undergo percutaneous coronary intervention (PCI) is relatively higher.

\section{The Mechanism of AGEs in Diabetic Cardiovascular Complications}

The effects of AGEs in the diabetic cardiovascular system are mediated by receptor-dependent and nonreceptordependent pathways (Figure 2). First, endothelial cell dysfunction is the starting event of atherosclerosis. AGEs can directly modify extracellular matrix proteins of endothelial cells, including type IV collagen and laminin $[75,76]$. This process destroys the normal structure and function of blood vessels, and cardiac fibrosis is accelerated [77]. AGEs not only damage endothelial cells but also induce apoptosis and dysfunction of endothelial progenitor cells [78]. Ueda et al.
[79] reported that serum AGE levels are independent risk factors for the number and function of circulating endothelial progenitor cells. In addition, AGEs can directly stimulate the production of vascular endothelial cell growth factor (VEGF), leading to increased vascular permeability or even vascular wall edema [80].

Additionally, circulating AGEs can increase lipid oxidation and deposition in atherosclerotic plaques and promote the infiltration of macrophages and $\mathrm{T}$ cell migration and proliferation, thereby promoting atherosclerosis [81]. AGE-induced LDL glycosylation results in the blocking of receptor-mediated LDL removal. Furthermore, increased glycosylation reduces the cholesterol reverse transport ability of HDL, thus promoting the deposition of lipids in blood vessel walls and resultant plaque formation $[82,83]$. Recent studies have also shown that the binding of AGEs to the platelet membrane receptor CD36 induces thrombus formation, which may be an important mechanism by which AGEs promote cardiac ischemic events in diabetic patients [84].

In addition, a recent study confirmed that the AGERAGE axis interacts with the RAS, which contributes to the proliferation of cardiac fibroblasts and cardiomyocyte hypertrophy in diabetes as well [85]. Moreover, it was reported that AGEs can upregulate RAGE expression via the activation of NF- $\kappa B$ [86]. As mentioned before, activated NF- $\kappa$ B binds to specific DNA sequences, regulating corresponding gene transcription and accelerating the emergence of cardiovascular complications. It is conceivable that the positive feedback loops between AGEs and RAGE-downstream pathways could create a vicious cycle, thus promoting cardiovascular complications in diabetes.

\section{Crosstalk between AGEs and Oxidative Stress in Diabetic Cardiovascular Complications}

Oxidative stress and the AGE-RAGE axle pathway are not independent processes. Accumulating evidence has suggested that the crosstalk between AGE-RAGE and oxidative stress plays an important role in the context of cardiovascular complications of diabetes [64]. AGE-RAGE interaction 


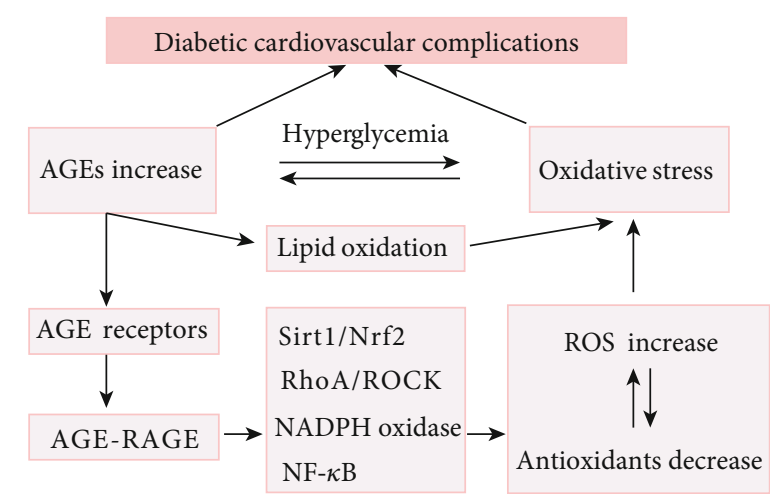

FIGURE 3: The interaction between AGE-RAGE axle and oxidative stress plays an important role in diabetic cardiovascular complications. On the one hand, AGE-RAGE axle activation can result in the activation of diverse signal transduction cascades, thereby including the generation of ROS and accelerating oxidative stress. On the other hand, excessive oxidative stress can in turn accelerate the generation of AGEs in the diabetic cardiovascular system.

results in the activation of diverse signal transduction cascades and downstream pathways such as MAPK, ERK1/2, p38, and NF- $\kappa \mathrm{B}$, thereby including the generation of ROS and accelerating oxidative stress and the emergence of cardiovascular complications in diabetes [87, 88]. Blockade of RAGEs attenuates vascular oxidative stress and the development of atherosclerosis.

Tang et al. reported that AGEs can activate NF- $\kappa$ B to increase the expression of inducible NO synthase (iNOS) through RAGE/RhoA/ROCK-mediated and AMPK-mediated signaling pathways, which subsequently promote the generation of NO in endothelial cells [89]. Hegab et al. found that treatment of cardiomyocytes with AGEs for $24 \mathrm{~h}$ significantly increased ROS production [90]. Chen et al. suggested that AGEs can induce oxidative stress through the Sirt1/Nrf2 axis by interacting with RAGEs under diabetic conditions [91]. AGEs were also reported to increase the expression and activity of NADPH oxidase in endothelial cells, which is an important source of oxidative stress in diabetic cardiovascular complications $[92,93]$. Increased NADPH oxidase activity results in the generation of ROS and the depletion of cellular antioxidants such as glutathione, glutathione peroxidase, superoxide dismutase, and catalase.

It was reported that AGEs are involved in a vicious cycle of oxidative stress [94]. AGEs modulate oxidative stress, and excessive oxidative stress can in turn accelerate the generation of AGEs [95] such as CML [96]. Taken together, these data suggest that the crosstalk between the AGE-RAGE axis and oxidative stress is highly involved in the context of diabetic cardiovascular complications (Figure 3). A deeper study of this relationship will facilitate the designing of new drugs and provide new prospects and methods for the prevention and treatment of diabetes and its cardiovascular complications. Drugs that deplete AGEs in the cardiovascular system or block their interaction with oxidative stress may be proper candidates.

\section{Current and Future Therapies against Diabetic Cardiovascular Complications}

Lifestyle changes, balanced energy intake, and glucose- and lipid-lowering drugs are the currently available treatment strategies for diabetes patients with cardiovascular complications [97]. A detailed description of therapeutic approaches for diabetes with cardiovascular complications is beyond the scope of this review. Since AGEs, oxidative stress, and their interactions are highly related to the progression of diabetic cardiovascular complications, therapies that involve AGEs and oxidative stress may help reduce the cardiovascular complications in diabetic patients (Table 1).

7.1. Traditional Antidiabetic Agents. Oscillating glucose is more deleterious to endothelial function and oxidative stress in type 2 diabetic patients $[98,99]$. Therefore, the key point for preventing and delaying the occurrence and development of diabetic cardiovascular complications lies in blood-glucose control [100]. In theory, a drug that lowers blood sugar confers cardiovascular protection, but actually, selective antidiabetic agents are limited. In contrast, some antidiabetic drugs even increase the risk of death from cardiovascular disease [101].

The UKPDS posttrial study and DCCT/EDIC showed that intensive blood-glucose control not only reduces the risk of microvascular disease in diabetes patients but also significantly reduces the total mortality rate of cardiovascular disease [102]. Intensive blood-glucose control with metformin is currently accepted to reduce the risk of cardiovascular disease in diabetes [103]. Its cardiovascular protection effect was attributed to the antioxidant properties that lead to the reduction of XO activity and lipid peroxidation in patients with type 2 diabetes [104]. Treatment of diabetic rats with metformin was also found to decrease the plasma levels of AGEs [105], thereby reducing oxidative stress and cardiac remodeling.

However, the conclusion of three other intensive hypoglycemic trials, ADVANCE, ACCORD and VADT, suggested that it may be difficult to effectively reduce cardiovascular risk in patients with type 2 diabetes simply by intensive glucose control [106]. Intensive hypoglycemic therapy increases the risk of hypoglycemia, which has been demonstrated to be significantly correlated with severe cardiovascular events in diabetes patients [107]. Moreover, since rosiglitazone was reported to be associated with a significant increase in the risk of myocardial infarction and death from cardiovascular events [108], the concern regarding the cardiovascular safety of antidiabetics has markedly increased even though, subsequently, the RECORD trial emphasized that rosiglitazone does not increase the risk of cardiovascular events [109].

7.2. Antioxidants. According to the "metabolic memory" theory, hyperglycemia-induced metabolic changes will last for a long time even after the blood-glucose level returns to normal $[106,110]$. Clearly, oxidative stress is considered the key cause of cardiovascular complications of diabetes. Therefore, antioxidant therapy and hypoglycemic therapy are equally important. 
TABLE 1: Therapeutic candidates against diabetic cardiovascular complications.

\begin{tabular}{|c|c|c|}
\hline Category & Examples & Mechanisms of act \\
\hline Traditional hypoglycemic agents & Metformin & $\begin{array}{l}\text { Antioxidant properties and possible } \\
\text { effects on the reduction of AGE }\end{array}$ \\
\hline \multirow{3}{*}{ Antioxidants } & Vitamin $\mathrm{C}$ and vitamin $\mathrm{E}$ & Antioxidant properties \\
\hline & ACEIs and ARBs & Reduce angiotensin II-induced oxidative stress \\
\hline & Statins & Reduce lipid peroxidation \\
\hline \multirow{3}{*}{ AGE-RAGE inhibitors } & ALT-711 & AGE cross-link breaker \\
\hline & Aminoguanidine & Inhibit AGE formation \\
\hline & Soluble RAGE & Competitively combine with AGEs \\
\hline \multirow{3}{*}{ New hypoglycemic agents } & GLP-1 receptor agonists & Not fully understood \\
\hline & DDP-4 inhibitors & Not fully understood \\
\hline & SGLT-2 inhibitors & Not fully understood \\
\hline
\end{tabular}

Antioxidants such as vitamins and vitamin analogs are widely used clinically. Vitamin $\mathrm{C}$ is a water-soluble vitamin that has significant antioxidant effects. Vitamin $\mathrm{C}$ infusion was reported to improve endothelial function and cardiac diastolic function. However, it did not alter the exercise capacity in type 2 diabetes [111]. Vitamin E can reduce lipid peroxidation in patients with noninsulin-dependent diabetes, which is important for the treatment of early diabetic cardiovascular complications [112]. Specifically, in patients with haptoglobin genotype-2 (Hp2-2), vitamin E has been shown to be associated with an approximately $35 \%$ reduction in cardiovascular diseases in both type 1 diabetes and type 2 diabetes $[113,114]$. This reduction was mediated partly by an improvement in the function of HDL. However, some clinical trial data suggest that vitamin E does not affect the development of cardiovascular diseases in some patients [115]. For vitamin $\mathrm{E}$ to be clinically used in diabetes, an additional large prospective study will be needed.

NADPH oxidase is the major source of ROS in oxidative stress under the condition of diabetes. Since angiotensin II can activate NADPH oxidase to increase oxidative stress through the AT1 receptor $[116,117]$, the administration of angiotensin-converting enzyme inhibitors (ACEIs) and angiotensin receptor blockers (ARBs) is currently the regular treatment for diabetes with cardiovascular complications. Statins were first known to reduce cholesterol synthesis through competitive inhibition of hydroxymethyl glutarate mononyl coenzyme A (HGM-CoA) reductase. An increasing number of studies have revealed that statins work as antioxidants beyond their lipid-lowering effect $[118,119]$. In patients receiving different treatments, the antioxidant state is independently affected but is significantly more pronounced in patients on statins [120]. This effect is mediated mainly by reducing the expression of NADPH oxidase subunit and increasing the expression of antioxidant enzyme [121].

7.3. AGE-RAGE Axis Inhibitors. Pharmacological inhibitors of AGEs include aminoguanidine (AG), pyridoxamine (a natural vitamin B6 derivative), benfotiamine, ACEIs, ARBs, statins, N-phenylthiazole bromide (ALT-711), and thiazolidinediones [122-124]. AG is a nucleophilic hydrazine complex that inhibits AGE formation by combining early glycosylation, glycogen oxidation products, acetaldehyde products, etc., subsequently attenuating AGE and ROS formation both in vivo and in vitro [125]. However, AG has been limited in further clinical usage because it interferes with several important regulatory systems and has yielded toxic side effects (such as flu-like symptoms, anemia, and gastrointestinal reactions) in clinical trials.

Reactive carbonyl compounds are precursors for the formation of AGEs, which significantly accelerate the formation of AGEs. Pyridoxamine acts as a nucleophilic compound that scavenges carbonyl compounds and is a possible mechanism by which pyridoxamine inhibits the formation of AGEs [126]. Nagai et al. [127] suggested that some metal ions, such as copper ions, can participate in the autooxidation of glucose and early glycation products, playing an important role in the formation of AGEs. Triethylenetetramine (TETA) was reported to induce antidiabetic changes by targeting these copper-mediated pathogenic mechanisms [31].

N-Phenylthiazole bromide (such as ALT-711 and TRC4186) can cleave the protein cross-linking structure in AGEs and reduce the accumulation of tissue AGEs. In vitro, collagen that cross-linked with AGEs incubated with ALT-711 was found to be more rapidly broken down by metalloproteinases [128]. Resveratrol treatment significantly reduces oxidative stress in the kidneys of rats with diabetes by downregulating RAGE [129]. Irisin alleviates AGE-induced inflammation and endothelial dysfunction by inhibiting ROS-NLRP3 inflammasome signaling [130]. However, the clinical application of the abovementioned agents in diabetes needs further study.

The molecular structure of RAGE includes its extracellular domain, transmembrane structure, and intracellular structure. Soluble RAGE (sRAGE) only contains the extracellular segment and can competitively combine with AGEs but cannot complete signal transduction, thus blocking the harmful effects of AGEs [131]. Studies have demonstrated that a high plasma level of sRAGE is independently associated with a low recurrence of atrial 
fibrillation after catheter ablation in diabetic patients [132]. AGEs and RAGE are increased in the atherosclerosis plaques in $\mathrm{apoE}^{-/-}$mice, whereas sRAGE treatment significantly reduces these changes [133]. Another study found that sRAGE can stabilize plaque and inhibit inflammatory factors such as cyclooxygenase-2 (COX-2), VCAM-1, and monocyte chemoattractant protein-1 (MCP-1), thereby reducing endothelial cell dysfunction [134].

7.4. New Hypoglycemic Agents. Although a series of drug candidates was reported to reduce oxidative stress and/or the AGE-RAGE axis, therapeutics that adequately address diabetic cardiovascular injuries have yet to be established clinically. Many trials of hypoglycemic therapy have also failed to prove that lowering blood glucose can effectively improve cardiovascular complications in patients with diabetes. Notably, several newly developed hypoglycemic drugs have been shown to exert a beneficial effect on the cardiovascular system beyond their ability to lower blood-glucose levels.

Glucagon-like peptide-1 (GLP-1) can stimulate endogenous insulin release. However, the half-life of GLP-1 is very short; once produced, it is degraded by dipeptidyl peptidase-4 (DDP-4) in short time [135]. New hypoglycemic agents, including DDP-4 inhibitors and GLP-1 receptor agonists, have been shown to have a beneficial effect on the cardiovascular system. The DPP-4 inhibitor sitagliptin is the first hypoglycemic agent to exhibit a comprehensive cardiovascular safety profile proven by a large randomized clinical trial [136]. The result of that study (TECOS) showed that sitagliptin therapy does not increase the incidence of cardiovascular endpoint events, which fully demonstrates its cardiovascular safety. According to the LEADER trial, the addition of the GLP-1 analog liraglutide to conventional treatment significantly reduced the incidence of cardiovascular end point events in patients with type 2 diabetes compared with the placebo group $[137,138]$.

Sodium-glucose cotransporter 2 (SGLT-2) inhibitors reduce the glucose concentration by selectively inhibiting SGLT2 in proximal renal tubules, thereby reducing glucose reabsorption and promoting glucose excretion. According to the EMPA-REG OUTCOME trial, an SGLT-2 inhibitor (empagliflozin) significantly reduced the risk of cardiovascular death in diabetes patients [139]. This result from EMPAREG OUTCOME showed that patients with type 2 diabetes who were at high risk of cardiovascular events had a significantly reduced risk of cardiovascular death (lowered by $38 \%$ ) when empagliflozin was added to the standard regimen [140]. The drug also reduced all-cause death risk (by 32\%) and hospitalizations due to heart failure (by 35\%) [141]. Animal studies revealed that empagliflozin treatment significantly reduces oxidative stress in cardiac tissues with no blood pressure reduction or improvement of cardiac autonomic dysfunction [142].

Currently, evidence of the effect of these new hypoglycemic agents on diabetic cardiovascular complications may be mediated through their ability beyond antidiabetic effects [143]. However, the direct mechanisms of these new hypoglycemic agents are not fully understood.

\section{Conclusions}

In summary, it is widely accepted that diabetes aggravates cardiovascular diseases and that patients with diabetic cardiovascular complications experience worse clinical outcomes. The abovementioned data suggest that AGE-RAGE axis inhibition or blockade of its interaction with oxidative stress is a novel therapeutic strategy for preventing cardiovascular complications in diabetes. The master role of AGEs and oxidative stress in cardiovascular complications of diabetes has been widely recognized, but many of these mechanisms are not yet clear and need further clarification since AGEs not only modulate oxidative stress but also in turn are affected by oxidative stress.

Fortunately, a series of drug candidates were reported to reduce oxidative stress and/or the AGE-RAGE axis. In addition, several new glucose-lowering drugs have also been found to exert a protective effect on the cardiovascular system beyond blood-glucose control in this population. A deeper study of these mechanisms and drugs will facilitate the designing of new drugs and provide new ideas for the prevention and treatment of diabetes and associated cardiovascular complications.

\section{Conflicts of Interest}

The authors declare that there is no conflict of interest regarding the publication of this paper.

\section{Acknowledgments}

This work was supported by grants from the Sichuan Medical Association (2018-2-1) and the Key Laboratory of Medical Electrophysiology (Southwest Medical University, KeyME2017-07).

\section{References}

[1] G. B. D. Disease, I. Injury, and C. Prevalence, "Global, regional, and national incidence, prevalence, and years lived with disability for 328 diseases and injuries for 195 countries, 1990-2016: a systematic analysis for the Global Burden of Disease Study 2016," The Lancet, vol. 390, no. 10100, pp. 1211-1259, 2017.

[2] N. H. Cho, J. E. Shaw, S. Karuranga et al., "IDF Diabetes Atlas: global estimates of diabetes prevalence for 2017 and projections for 2045," Diabetes Research and Clinical Practice, vol. 138, pp. 271-281, 2018.

[3] S. Basu, J. S. Yudkin, S. Kehlenbrink et al., "Estimation of global insulin use for type 2 diabetes, 2018-30: a microsimulation analysis," The Lancet Diabetes \& Endocrinology, vol. 7, no. 1, pp. 25-33, 2019.

[4] F. Paneni and T. F. Luscher, "Cardiovascular protection in the treatment of type 2 diabetes: a review of clinical trial results across drug classes," The American Journal of Cardiology, vol. 120, no. 1S, pp. S17-S27, 2017.

[5] C. Sardu, C. De Lucia, M. Wallner, and G. Santulli, "Diabetes mellitus and its cardiovascular complications: new insights into an old disease," Journal Diabetes Research, vol. 2019, article 1905194, 2 pages, 2019. 
[6] G. Jia, A. Whaley-Connell, and J. R. Sowers, "Diabetic cardiomyopathy: a hyperglycaemia- and insulin-resistance-induced heart disease," Diabetologia, vol. 61, no. 1, pp. 21-28, 2018.

[7] R. Madonna, D. Pieragostino, C. R. Balistreri et al., "Diabetic macroangiopathy: pathogenetic insights and novel therapeutic approaches with focus on high glucose-mediated vascular damage," Vascular Pharmacology, vol. 107, pp. 27-34, 2018.

[8] R. Madonna, C. R. Balistreri, Y. J. Geng, and R. de Caterina, "Diabetic microangiopathy: pathogenetic insights and novel therapeutic approaches," Vascular Pharmacology, vol. 90, pp. 1-7, 2017.

[9] A. Poudel, J. Y. Zhou, D. Story, and L. Li, "Diabetes and associated cardiovascular complications in American Indians/Alaskan Natives: a review of risks and prevention strategies," Journal Diabetes Research, vol. 2018, article 2742565, 8 pages, 2018.

[10] L. Pozo, F. Bello, A. Suarez et al., "Novel pharmacological therapy in type 2 diabetes mellitus with established cardiovascular disease: current evidence," World Journal of Diabetes, vol. 10, no. 5, pp. 291-303, 2019.

[11] M. H. Hangaard, P. Rossing, J. S. Jensen, and M. T. Jensen, "Heart failure often accompanies diabetes mellitus," Ugeskr Laeger, vol. 180, no. 20A, 2018.

[12] K. Umamahesh, A. Vigneswari, G. Surya Thejaswi, K. Satyavani, and V. Viswanathan, "Incidence of cardiovascular diseases and associated risk factors among subjects with type 2 diabetes - an 11-year follow up study," Indian Heart Journal, vol. 66, no. 1, pp. 5-10, 2014.

[13] J. M. Mostaza-Prieto, L. Martín-Jadraque, I. López et al., "Evidence-based cardiovascular therapies and achievement of therapeutic goals in diabetic patients with coronary heart disease attended in primary care," American Heart Journal, vol. 152, no. 6, pp. 1064-1070, 2006.

[14] J. C. Jha, F. Ho, C. Dan, and K. Jandeleit-Dahm, "A causal link between oxidative stress and inflammation in cardiovascular and renal complications of diabetes," Clinical Science, vol. 132, no. 16, pp. 1811-1836, 2018.

[15] P. K. Bagul and S. K. Banerjee, "Insulin resistance, oxidative stress and cardiovascular complications: role of sirtuins," Current Pharmaceutical Design, vol. 19, no. 32, pp. 5663$5677,2013$.

[16] I. Idris, S. Gray, and R. Donnelly, "Protein kinase C activation: isozyme-specific effects on metabolism and cardiovascular complications in diabetes," Diabetologia, vol. 44, no. 6, pp. 659-673, 2001.

[17] D. Pedicino, G. Liuzzo, F. Trotta et al., "Adaptive immunity, inflammation, and cardiovascular complications in type 1 and type 2 diabetes mellitus," Journal of Diabetes Research, vol. 2013, Article ID 184258, 11 pages, 2013.

[18] A. Festa and S. M. Haffner, "Inflammation and cardiovascular disease in patients with diabetes: lessons from the Diabetes Control and Complications Trial," Circulation, vol. 111, no. 19, pp. 2414-2415, 2005.

[19] C. Vernochet, F. Damilano, A. Mourier et al., "Adipose tissue mitochondrial dysfunction triggers a lipodystrophic syndrome with insulin resistance, hepatosteatosis, and cardiovascular complications," The FASEB Journal, vol. 28, no. 10, pp. 4408-4419, 2014.

[20] T. Hayashi, S. Takai, and C. Yamashita, "Impact of the reninangiotensin-aldosterone-system on cardiovascular and renal complications in diabetes mellitus," Current Vascular Pharmacology, vol. 8, no. 2, pp. 189-197, 2010.

[21] M. S. Shah and M. Brownlee, "Molecular and cellular mechanisms of cardiovascular disorders in diabetes," Circulation Research, vol. 118, no. 11, pp. 1808-1829, 2016.

[22] A. Faria and S. J. Persaud, "Cardiac oxidative stress in diabetes: mechanisms and therapeutic potential," Pharmacology \& Therapeutics, vol. 172, pp. 50-62, 2017.

[23] X. F. Hu, L. Wang, G. Xiang, W. Lei, and Y. F. Feng, "Angiogenesis impairment by the NADPH oxidase-triggered oxidative stress at the bone-implant interface: critical mechanisms and therapeutic targets for implant failure under hyperglycemic conditions in diabetes," Acta Biomaterialia, vol. 73, pp. 470-487, 2018.

[24] S. Lamas and T. Michel, "Introduction to special issue "Redox regulation of cardiovascular signaling in health and disease"," Free Radical Biology \& Medicine, vol. 109, pp. 1-3, 2017.

[25] Y. Wen, R. Liu, N. Lin et al., "NADPH oxidase hyperactivity contributes to cardiac dysfunction and apoptosis in rats with severe experimental pancreatitis through ROS-mediated MAPK signaling pathway," Oxidative Medicine and Cellular Longevity, vol. 2019, Article ID 4578175, 18 pages, 2019.

[26] L. C. Sanchez-Aranguren, C. T. Espinosa-Gonzalez, L. M. Gonzalez-Ortiz et al., "Soluble Fms-like tyrosine kinase-1 alters cellular metabolism and mitochondrial bioenergetics in preeclampsia," Frontiers in Physiology, vol. 9, p. 83, 2018.

[27] J. Maiuolo, A. Maretta, M. Gliozzi et al., "Ethanol-induced cardiomyocyte toxicity implicit autophagy and NFkB transcription factor," Pharmacological Research, vol. 133, pp. 141-150, 2018.

[28] N. R. Madamanchi and M. S. Runge, "Redox signaling in cardiovascular health and disease," Free Radical Biology \& Medicine, vol. 61, pp. 473-501, 2013.

[29] J. J. Peng, S. Q. Xiong, L. X. Ding, J. Peng, and X. B. Xia, “Diabetic retinopathy: focus on NADPH oxidase and its potential as therapeutic target," European Journal of Pharmacology, vol. 853, pp. 381-387, 2019.

[30] K. Suriyaprom, S. Kaewprasert, P. Putpadungwipon, P. Namjuntra, and S. Klongthalay, "Association of antioxidant status and inflammatory markers with metabolic syndrome in Thais," Journal of Health, Population and Nutrition, vol. 38, no. 1, p. 1, 2019.

[31] G. J. S. Cooper, "Selective divalent copper chelation for the treatment of diabetes mellitus," Current Medicinal Chemistry, vol. 19, no. 17, pp. 2828-2860, 2012.

[32] N. Sallam and I. Laher, "Exercise modulates oxidative stress and inflammation in aging and cardiovascular diseases," Oxidative Medicine and Cellular Longevity, vol. 2016, Article ID 7239639, 32 pages, 2016.

[33] C. P. Domingueti, L. M. S.'. A. Dusse, M. d. G. Carvalho, L. P. de Sousa, K. B. Gomes, and A. P. Fernandes, "Diabetes mellitus: the linkage between oxidative stress, inflammation, hypercoagulability and vascular complications," Journal of Diabetes and its Complications, vol. 30, no. 4, pp. 738-745, 2016.

[34] S. Lee, H. Zhang, J. Chen, K. C. Dellsperger, M. A. Hill, and C. Zhang, "Adiponectin abates diabetes-induced endothelial dysfunction by suppressing oxidative stress, adhesion molecules, and inflammation in type 2 diabetic mice," American Journal of Physiology Heart and Circulatory Physiology, vol. 303, no. 1, pp. H106-H115, 2012. 
[35] A. W. Wang, L. Song, J. Miao et al., "Baicalein attenuates angiotensin II-induced cardiac remodeling via inhibition of $\mathrm{AKT} / \mathrm{mTOR}$, ERK1/2, NF- $\kappa \mathrm{B}$, and calcineurin signaling pathways in mice," American Journal of Hypertension, vol. 28, no. 4, pp. 518-526, 2015.

[36] M. P. A. Baldassarre, A. Andersen, A. Consoli, F. K. Knop, and T. Vilsbøll, "Cardiovascular biomarkers in clinical studies of type 2 diabetes," Diabetes, Obesity \& Metabolism, vol. 20, no. 6, pp. 1350-1360, 2018.

[37] M. I. Saad, T. M. Abdelkhalek, M. M. Saleh et al., "Insights into the molecular mechanisms of diabetes-induced endothelial dysfunction: focus on oxidative stress and endothelial progenitor cells," Endocrine, vol. 50, no. 3, pp. 537-567, 2015.

[38] M. C. Bertoluci, G. V. Ce, A. M. da Silva, M. V. Wainstein, W. Boff, and M. Puñales, "Endothelial dysfunction as a predictor of cardiovascular disease in type 1 diabetes," World Journal of Diabetes, vol. 6, no. 5, pp. 679-692, 2015.

[39] J. Tanaka, L. Qiang, A. S. Banks et al., "Foxo1 links hyperglycemia to LDL oxidation and endothelial nitric oxide synthase dysfunction in vascular endothelial cells," Diabetes, vol. 58, no. 10, pp. 2344-2354, 2009.

[40] C. Szabo, "Role of nitrosative stress in the pathogenesis of diabetic vascular dysfunction," British Journal of Pharmacology, vol. 156, no. 5, pp. 713-727, 2009.

[41] J. D. Moreira, L. Pernomian, M. S. Gomes et al., "Enhanced nitric oxide generation from nitric oxide synthases as the cause of increased peroxynitrite formation during acute restraint stress: effects on carotid responsiveness to angiotensinergic stimuli in type-1 diabetic rats," European Journal of Pharmacology, vol. 783, pp. 11-22, 2016.

[42] K. Huynh, H. Kiriazis, X. J. Du et al., "Coenzyme $Q_{10}$ attenuates diastolic dysfunction, cardiomyocyte hypertrophy and cardiac fibrosis in the $d b / d b$ mouse model of type 2 diabetes," Diabetologia, vol. 55, no. 5, pp. 1544-1553, 2012.

[43] E. Liang, X. Liu, Z. Du, R. Yang, and Y. Zhao, “Andrographolide Ameliorates Diabetic Cardiomyopathy in Mice by Blockage of Oxidative Damage and NF- $\kappa$ B-Mediated Inflammation," Oxidative Medicine and Cellular Longevity, vol. 2018, Article ID 9086747, 13 pages, 2018.

[44] M. E. Cooper, "The role of the renin-angiotensin-aldosterone system in diabetes and its vascular complications," American Journal of Hypertension, vol. 17, 11 Part 2, article S0895706104009586, pp. S16-S20, 2004.

[45] Y. Ohshiro, R. C. Ma, Y. Yasuda et al., "Reduction of diabetesinduced oxidative stress, fibrotic cytokine expression, and renal dysfunction in protein kinase Cbeta-null mice," Diabetes, vol. 55, no. 11, pp. 3112-3120, 2006.

[46] Z. J. Cheng, H. Vapaatalo, and E. Mervaala, "Angiotensin II and vascular inflammation," Medical Science Monitor, vol. 11, no. 6, pp. RA194-RA205, 2005.

[47] F. Fiordaliso, I. Cuccovillo, R. Bianchi et al., "Cardiovascular oxidative stress is reduced by an ACE inhibitor in a rat model of streptozotocin-induced diabetes," Life Sciences, vol. 79, no. 2, pp. 121-129, 2006.

[48] P. Manna and P. C. Sil, "Impaired redox signaling and mitochondrial uncoupling contributes vascular inflammation and cardiac dysfunction in type 1 diabetes: protective role of arjunolic acid," Biochimie, vol. 94, no. 3, pp. 786-797, 2012.

[49] E. R. Dabkowski, W. A. Baseler, C. L. Williamson et al., "Mitochondrial dysfunction in the type 2 diabetic heart is associated with alterations in spatially distinct mitochondrial proteomes," American Journal of Physiology-Heart and Circulatory Physiology, vol. 299, no. 2, pp. H529-H540, 2010.

[50] G. Qin, M. Wu, J. Wang, Z. Xu, J. Xia, and N. Sang, "Sulfur dioxide contributes to the cardiac and mitochondrial dysfunction in rats," Toxicological Sciences, vol. 151, no. 2, pp. 334-346, 2016.

[51] L. E. Formosa, A. Hofer, C. Tischner, T. Wenz, and M. T. Ryan, "Translation and assembly of radiolabeled mitochondrial DNA-encoded protein subunits from cultured cells and isolated mitochondria," Methods in Molecular Biology, vol. 1351, pp. 115-129, 2016.

[52] L. Gao, K. Laude, and H. Cai, "Mitochondrial pathophysiology, reactive oxygen species, and cardiovascular diseases," Veterinary Clinics of North America: Small Animal Practice, vol. 38, no. 1, pp. 137-155, 2008.

[53] V. Kain, S. Kumar, and S. L. Sitasawad, “Azelnidipine prevents cardiac dysfunction in streptozotocin-diabetic rats by reducing intracellular calcium accumulation, oxidative stress and apoptosis," Cardiovascular Diabetology, vol. 10, no. 1, p. 97, 2011.

[54] A. Eirin, B. Ebrahimi, S. H. Kwon et al., "Restoration of mitochondrial cardiolipin attenuates cardiac damage in swine renovascular hypertension," Journal of the American Heart Association, vol. 5, no. 6, article e003118, 2016.

[55] M. Hellwig and T. Henle, "Baking, ageing, diabetes: a short history of the Maillard reaction," Angewandte Chemie International Edition, vol. 53, no. 39, pp. 10316-10329, 2014.

[56] M. Heilmann, A. Wellner, G. Gadermaier et al., "Ovalbumin modified with pyrraline, a Maillard reaction product, shows enhanced T-cell immunogenicity," The Journal of Biological Chemistry, vol. 289, no. 11, pp. 7919-7928, 2014.

[57] K. Kankova, "Diabetic threesome (hyperglycaemia, renal function and nutrition) and advanced glycation end products: evidence for the multiple-hit agent?," The Proceedings of the Nutrition Society, vol. 67, no. 1, pp. 60-74, 2008.

[58] H. Drenth, S. U. Zuidema, W. P. Krijnen et al., "Advanced glycation end products are associated with physical activity and physical functioning in the older population," The Journals of Gerontology Series A, Biological Sciences and Medical Sciences, vol. 73, no. 11, pp. 1545-1551, 2018.

[59] J. Xue, V. Rai, D. Singer et al., "Advanced glycation end product recognition by the receptor for AGEs," Structure, vol. 19, no. 5, pp. 722-732, 2011.

[60] N. Ohgami, R. Nagai, M. Ikemoto et al., "CD36, a member of class B scavenger receptor family, is a receptor for advanced glycation end products," Annals of the New York Academy of Sciences, vol. 947, no. 1, pp. 350-355, 2001.

[61] S. Ahmad, H. Khan, Z. Siddiqui et al., "AGEs, RAGEs and s-RAGE; friend or foe for cancer," Seminars in Cancer Biology, vol. 49, pp. 44-55, 2018.

[62] H. O. Al-Mesallamy, L. N. Hammad, T. A. El-Mamoun, and B. M. Khalil, "Role of advanced glycation end product receptors in the pathogenesis of diabetic retinopathy," Journal of Diabetes and its Complications, vol. 25, no. 3, pp. 168-174, 2011.

[63] H. Pageon, H. Zucchi, F. Rousset, V. M. Monnier, and D. Asselineau, "Skin aging by glycation: lessons from the reconstructed skin model," Clinical Chemistry and Laboratory Medicine, vol. 52, no. 1, pp. 169-174, 2014.

[64] S. Yamagishi, S. Maeda, T. Matsui, S. Ueda, K. Fukami, and S. Okuda, "Role of advanced glycation end products (AGEs) 
and oxidative stress in vascular complications in diabetes," Biochimica et Biophysica Acta, vol. 1820, no. 5, pp. 663-671, 2012.

[65] K. M. Reiser, "Nonenzymatic glycation of collagen in aging and diabetes," Proceedings of the Society for Experimental Biology and Medicine, vol. 218, no. 1, pp. 23-37, 1998.

[66] C. Wihler, S. Schafer, K. Schmid et al., "Renal accumulation and clearance of advanced glycation end-products in type 2 diabetic nephropathy: effect of angiotensin-converting enzyme and vasopeptidase inhibition," Diabetologia, vol. 48, no. 8, pp. 1645-1653, 2005.

[67] A. E. Stinghen, Z. A. Massy, H. Vlassara, G. E. Striker, and A. Boullier, "Uremic toxicity of advanced glycation end products in CKD," Journal of the American Society of Nephrology, vol. 27, no. 2, pp. 354-370, 2016.

[68] N. Reiniger, K. Lau, D. McCalla et al., "Deletion of the receptor for advanced glycation end products reduces glomerulosclerosis and preserves renal function in the diabetic OVE26 mouse," Diabetes, vol. 59, no. 8, pp. 2043-2054, 2010.

[69] H. Sugimoto, G. Grahovac, M. Zeisberg, and R. Kalluri, "Renal fibrosis and glomerulosclerosis in a new mouse model of diabetic nephropathy and its regression by bone morphogenic protein-7 and advanced glycation end product inhibitors," Diabetes, vol. 56, no. 7, pp. 1825-1833, 2007.

[70] J. W. Nin, A. Jorsal, I. Ferreira et al., "Higher plasma levels of advanced glycation end products are associated with incident cardiovascular disease and all-cause mortality in type 1 diabetes: a 12-year follow-up study," Diabetes Care, vol. 34, no. 2, pp. 442-447, 2011.

[71] K. Steine, J. R. Larsen, M. Stugaard, T. J. Berg, M. Brekke, and K. Dahl-Jørgensen, "LV systolic impairment in patients with asymptomatic coronary heart disease and type 1 diabetes is related to coronary atherosclerosis, glycaemic control and advanced glycation endproducts," European Journal of Heart Failure, vol. 9, no. 10, pp. 1044-1050, 2007.

[72] T. J. Berg, O. Snorgaard, J. Faber et al., "Serum levels of advanced glycation end products are associated with left ventricular diastolic function in patients with type 1 diabetes," Diabetes Care, vol. 22, no. 7, pp. 1186-1190, 1999.

[73] G. Jia, M. A. Hill, and J. R. Sowers, "Diabetic cardiomyopathy: an update of mechanisms contributing to this clinical entity," Circulation Research, vol. 122, no. 4, pp. 624-638, 2018.

[74] C. Spadaccio, G. Patti, F. de Marco et al., "Usefulness of preprocedural levels of advanced glycation end products to predict restenosis in patients with controlled diabetes mellitus undergoing drug-eluting stent implantation for stable angina pectoris (from the Prospective ARMYDA-AGEs Study)," The American Journal of Cardiology, vol. 112, no. 1, pp. 21-26, 2013.

[75] O. Simo-Servat, R. Simo, and C. Hernandez, "Circulating biomarkers of diabetic retinopathy: an overview based on physiopathology," Journal Diabetes Research, vol. 2016, article 5263798, 13 pages, 2016.

[76] V. Thallas-Bonke, C. Lindschau, B. Rizkalla et al., “Attenuation of extracellular matrix accumulation in diabetic nephropathy by the advanced glycation end product crosslink breaker ALT-711 via a protein kinase C- $\alpha$-Dependent pathway," Diabetes, vol. 53, no. 11, pp. 2921-2930, 2004.

[77] J. Zhao, R. Randive, and J. A. Stewart, "Molecular mechanisms of AGE/RAGE-mediated fibrosis in the diabetic heart," World Journal of Diabetes, vol. 5, no. 6, pp. 860-867, 2014.
[78] J. H. Kim, K. A. Kim, Y. J. Shin, H. Kim, A. Majid, and O. N. Bae, "Methylglyoxal induced advanced glycation end products (AGE)/receptor for AGE (RAGE)-mediated angiogenic impairment in bone marrow-derived endothelial progenitor cells," Journal of Toxicology and Environmental Health: Part A, vol. 81, no. 9, pp. 266-277, 2018.

[79] S. Ueda, S. Yamagishi, T. Matsui et al., "Serum levels of advanced glycation end products (AGEs) are inversely associated with the number and migratory activity of circulating endothelial progenitor cells in apparently healthy subjects," Cardiovascular Therapeutics, vol. 30, no. 4, pp. 249-254, 2012.

[80] M. Saboor, M. Ajmal, and S. Ilyas, "Functional status of vascular endothelium in diabetes mellitus," Journal of Ayub Medical College, Abbottabad, vol. 26, no. 2, pp. 239-243, 2014.

[81] G. Garg, S. Singh, A. K. Singh, and S. I. Rizvi, "Metformin alleviates altered erythrocyte redox status during aging in rats," Rejuvenation Research, vol. 20, no. 1, pp. 15-24, 2017.

[82] S. Ahmad, F. Akhter, Moinuddin, U. Shahab, and M. S. Khan, "Studies on glycation of human low density lipoprotein: a functional insight into physico-chemical analysis," International Journal of Biological Macromolecules, vol. 62, pp. 167-171, 2013.

[83] M. Femlak, A. Gluba-Brzozka, A. Cialkowska-Rysz, and J. Rysz, "The role and function of HDL in patients with diabetes mellitus and the related cardiovascular risk," Lipids in Health and Disease, vol. 16, no. 1, p. 207, 2017.

[84] W. Zhu, W. Li, and R. L. Silverstein, "Advanced glycation end products induce a prothrombotic phenotype in mice via interaction with platelet CD36," Blood, vol. 119, no. 25, pp. 6136-6144, 2012.

[85] K. G. Yamazaki, E. Gonzalez, and A. C. Zambon, "Crosstalk between the renin-angiotensin system and the advance glycation end product axis in the heart: role of the cardiac fibroblast," Journal of Cardiovascular Translational Research, vol. 5, no. 6, pp. 805-813, 2012.

[86] N. Mahajan and V. Dhawan, "Receptor for advanced glycation end products (RAGE) in vascular and inflammatory diseases," International Journal of Cardiology, vol. 168, no. 3, pp. 1788-1794, 2013.

[87] N. Lin, H. Zhang, and Q. Su, "Les produits terminaux de la glycation avancee lesent les cellules $\beta$ des ilots de Langerhans du pancreas par le stress oxydant," Diabetes \& Metabolism, vol. 38, no. 3, pp. 250-257, 2012.

[88] Q. Zhou, K. W. Cheng, J. Gong, E. T. S. Li, and M. Wang, "Apigenin and its methylglyoxal-adduct inhibit advanced glycation end products- induced oxidative stress and inflammation in endothelial cells," Biochemical Pharmacology, vol. 166, pp. 231-241, 2019.

[89] S. T. Tang, Q. Zhang, H. Q. Tang et al., "Effects of glucagonlike peptide-1 on advanced glycation endproduct-induced aortic endothelial dysfunction in streptozotocin-induced diabetic rats: possible roles of rho kinase- and AMP kinasemediated nuclear factor $\kappa \mathrm{B}$ signaling pathways," Endocrine, vol. 53, no. 1, pp. 107-116, 2016.

[90] Z. Hegab, T. M. A. Mohamed, N. Stafford, M. Mamas, E. J. Cartwright, and D. Oceandy, "Advanced glycation end products reduce the calcium transient in cardiomyocytes by increasing production of reactive oxygen species and nitric oxide," FEBS Open Bio, vol. 7, no. 11, pp. 1672-1685, 2017. 
[91] X. J. Chen, W. J. Wu, Q. Zhou et al., "Advanced glycation end-products induce oxidative stress through the Sirt1/Nrf2 axis by interacting with the receptor of AGEs under diabetic conditions," Journal of Cellular Biochemistry, vol. 120, no. 2, pp. 2159-2170, 2018.

[92] Y. H. Chen, Z. W. Chen, H. M. Li, X. F. Yan, and B. Feng, "AGE/RAGE-induced EMP release via the NOX-derived ROS pathway," Journal of Diabetes Research, vol. 2018, Article ID 6823058, 8 pages, 2018.

[93] X. Ren, L. Ren, Q. Wei, H. Shao, L. Chen, and N. Liu, "Advanced glycation end-products decreases expression of endothelial nitric oxide synthase through oxidative stress in human coronary artery endothelial cells," Cardiovascular Diabetology, vol. 16, no. 1, p. 52, 2017.

[94] N. C. Chilelli, S. Burlina, and A. Lapolla, "AGEs, rather than hyperglycemia, are responsible for microvascular complications in diabetes: A "glycoxidation-centric" point of view," Nutrition, Metabolism, and Cardiovascular Diseases, vol. 23, no. 10, pp. 913-919, 2013.

[95] A. Dobi, S. B. Bravo, B. Veeren et al., "Advanced glycation end-products disrupt human endothelial cells redox homeostasis: new insights into reactive oxygen species production," Free Radical Research, vol. 53, no. 2, pp. 150-169, 2019.

[96] W. Q. Ma, X. Q. Han, Y. Wang, X. Wang, Y. Zhu, and N. F. Liu, "NE-carboxymethyl-lysine promotes calcium deposition in VSMCs via intracellular oxidative stress-induced PDK4 activation and alters glucose metabolism," Oncotarget, vol. 8, no. 68, pp. 112841-112854, 2017.

[97] C. C. Low Wang, C. N. Hess, W. R. Hiatt, and A. B. Goldfine, "Clinical update: cardiovascular disease in diabetes mellitus: atherosclerotic cardiovascular disease and heart failure in type 2 diabetes mellitus-mechanisms, management, and clinical considerations," Circulation, vol. 133, no. 24, pp. 24592502, 2016.

[98] L. La Sala, M. Cattaneo, V. De Nigris et al., "Oscillating glucose induces microRNA-185 and impairs an efficient antioxidant response in human endothelial cells," Cardiovascular Diabetology, vol. 15, no. 1, p. 71, 2016.

[99] A. Ceriello, K. Esposito, L. Piconi et al., "Oscillating glucose is more deleterious to endothelial function and oxidative stress than mean glucose in normal and type 2 diabetic patients," Diabetes, vol. 57, no. 5, pp. 1349-1354, 2008.

[100] S. Zoungas, J. Chalmers, B. Neal et al., "Follow-up of bloodpressure lowering and glucose control in type 2 diabetes," The New England Journal of Medicine, vol. 371, no. 15, pp. 1392-1406, 2014.

[101] S. E. Nissen and K. Wolski, "Effect of rosiglitazone on the risk of myocardial infarction and death from cardiovascular causes," The New England Journal of Medicine, vol. 356, no. 24, pp. 2457-2471, 2007.

[102] C. Cugnet-Anceau and B. Bauduceau, "Équilibre glycemique et morbimortalite cardiovasculaire apport des etudes 2008," Annales d'endocrinologie, vol. 70, no. 1, pp. 48-54, 2009.

[103] X. Xie and H. Vondeling, "Cost-utility analysis of intensive blood glucose control with metformin versus usual care in overweight type 2 diabetes mellitus patients in Beijing, P.R. China," Value in Health, vol. 11, Supplement 1, pp. S23-S32, 2008.

[104] G. Ansari, M. Mojtahedzadeh, F. Kajbaf et al., "How does blood glucose control with metformin influence intensive insulin protocols? Evidence for involvement of oxidative stress and inflammatory cytokines," Advances in Therapy, vol. 25 , no. 7 , pp. 681-702, 2008 .

[105] M. Haddad, I. Knani, H. Bouzidi, O. Berriche, M. Hammami, and M. Kerkeni, "Plasma levels of pentosidine, carboxymethyl-lysine, soluble receptor for advanced glycation end products, and metabolic syndrome: the metformin effect," Disease Markers, vol. 2016, Article ID 6248264, 8 pages, 2016.

[106] A. Misra and Z. Bloomgarden, "Metabolic memory: evolving concepts," Journal of Diabetes, vol. 10, no. 3, pp. 186-187, 2018.

[107] B. W. Paty, "The role of hypoglycemia in cardiovascular outcomes in diabetes," Canadian Journal of Diabetes, vol. 39, Supplement 5, pp. S155-S159, 2015.

[108] E. Mannucci, M. Monami, and N. Marchionni, "Rosiglitazone and cardiovascular risk," The New England Journal of Medicine, vol. 356, no. 24, pp. 2522-2524, 2007.

[109] J. J. DiNicolantonio and P. Meier, "Is rosiglitazone as safe as BARI 2D and the reanalysis of RECORD imply?," Cardiology, vol. 127, no. 3, pp. 152-154, 2014.

[110] R. Testa, A. R. Bonfigli, F. Prattichizzo, L. la Sala, V. de Nigris, and A. Ceriello, "The "metabolic memory" theory and the early treatment of hyperglycemia in prevention of diabetic complications," Nutrients, vol. 9, no. 5, p. 437, 2017.

[111] R. L. Scalzo, T. A. Bauer, K. Harrall et al., "Acute vitamin C improves cardiac function, not exercise capacity, in adults with type 2 diabetes," Diabetology \& Metabolic Syndrome, vol. 10, no. 1, p. 7, 2018

[112] K. Zwirska-Korczala, J. Jagodzinska, T. Wielkoszynski et al., "Assessment of plasma lipid profile oxysterols and vitamin E concentration in morbidity obese patients with coexisting arterial hypertension and non-insulin dependent diabetes mellitus," Polskie Archiwum Medycyny Wewnętrznej, vol. 107, no. 2, pp. 141-147, 2002.

[113] I. Hochberg, E. M. Berinstein, U. Milman, C. Shapira, and A. P. Levy, "Interaction between the haptoglobin genotype and vitamin $\mathrm{E}$ on cardiovascular disease in diabetes," Current Diabetes Reports, vol. 17, no. 6, p. 42, 2017.

[114] S. Blum, M. Vardi, J. B. Brown et al., "Vitamin E reduces cardiovascular disease in individuals with diabetes mellitus and the haptoglobin 2-2 genotype," Pharmacogenomics, vol. 11, no. 5, pp. 675-684, 2010.

[115] T. Costacou, A. P. Levy, R. G. Miller et al., "Effect of vitamin E supplementation on HDL function by haptoglobin genotype in type 1 diabetes: results from the HapE randomized crossover pilot trial," Acta Diabetologica, vol. 53, no. 2, pp. 243250, 2016.

[116] M. L. Onozato, A. Tojo, A. Goto, T. Fujita, and C. S. Wilcox, "Oxidative stress and nitric oxide synthase in rat diabetic nephropathy: effects of ACEI and ARB," Kidney International, vol. 61, no. 1, pp. 186-194, 2002.

[117] G. Zhou, U. Johansson, X. R. Peng, K. Bamberg, and Y. Huang, "An additive effect of eplerenone to ACE inhibitor on slowing the progression of diabetic nephropathy in the $\mathrm{db} / \mathrm{db}$ mice," American Journal of Translational Research, vol. 8, no. 3, pp. 1339-1354, 2016.

[118] N. Schupp, U. Schmid, A. Heidland, and H. Stopper, "Rosuvastatin protects against oxidative stress and DNA damage _in vitro_via upregulation of glutathione synthesis," Atherosclerosis, vol. 199, no. 2, pp. 278-287, 2008.

[119] N. Sawada and J. K. Liao, "Rho/rho-associated coiled-coil forming kinase pathway as therapeutic targets for statins in 
atherosclerosis," Antioxidants \& Redox Signaling, vol. 20, no. 8, pp. 1251-1267, 2014.

[120] I. L. Megson, A. T. Treweeke, A. Shaw et al., "Continuous subcutaneous insulin infusion in patients with type 2 diabetes: a cohort study to establish the relationship between glucose control and plasma oxidized low density lipoprotein," Journal of Diabetes Science and Technology, vol. 9, no. 3, pp. 573-580, 2015.

[121] T. Shida, T. Nozawa, M. Sobajima, H. Ihori, A. Matsuki, and H. Inoue, "Fluvastatin-induced reduction of oxidative stress ameliorates diabetic cardiomyopathy in association with improving coronary microvasculature," Heart and Vessels, vol. 29, no. 4, pp. 532-541, 2014.

[122] A. Nenna, F. Nappi, S. S. Avtaar Singh et al., "Pharmacologic approaches against advanced glycation end products (AGEs) in diabetic cardiovascular disease," Research in Cardiovascular Medicine, vol. 4, no. 2, article e26949, 2015.

[123] D. J. Borg and J. M. Forbes, "Targeting advanced glycation with pharmaceutical agents: where are we now?," Glycoconjugate Journal, vol. 33, no. 4, pp. 653-670, 2016.

[124] P. Balakumar, A. Rohilla, P. Krishan, P. Solairaj, and A. Thangathirupathi, "The multifaceted therapeutic potential of benfotiamine," Pharmacological Research, vol. 61, no. 6, pp. 482-488, 2010.

[125] J. Kim, C. S. Kim, E. Sohn et al., "Aminoguanidine protects against apoptosis of retinal ganglion cells in Zucker diabetic fatty rats," European Review for Medical and Pharmacological Sciences, vol. 18, no. 11, pp. 1573-1578, 2014.

[126] D. Deluyker, V. Ferferieva, R. B. Driesen, M. Verboven, I. Lambrichts, and V. Bito, "Pyridoxamine improves survival and limits cardiac dysfunction after MI," Scientific Reports, vol. 7, no. 1, article 16010, 2017.

[127] R. Nagai, D. B. Murray, T. O. Metz, and J. W. Baynes, "Chelation: a fundamental mechanism of action of AGE inhibitors, AGE breakers, and other inhibitors of diabetes complications," Diabetes, vol. 61, no. 3, pp. 549-559, 2012.

[128] S. J. Zieman, V. Melenovsky, L. Clattenburg et al., "Advanced glycation endproduct crosslink breaker (alagebrium) improves endothelial function in patients with isolated systolic hypertension," Journal of Hypertension, vol. 25, no. 3, pp. 577-583, 2007.

[129] H. Moridi, J. Karimi, N. Sheikh et al., "Resveratrol-dependent down-regulation of receptor for advanced glycation End Products and oxidative stress in kidney of rats with diabetes," International Journal of Endocrinology and Metabolism, vol. 13, no. 2, article e23542, 2015.

[130] X. Deng, W. Huang, J. Peng et al., "Irisin alleviates advanced glycation end products-induced inflammation and endothelial dysfunction via inhibiting ROS-NLRP3 inflammasome signaling," Inflammation, vol. 41, no. 1, pp. 260-275, 2018.

[131] V. Kumar, A. Sulaj, T. Fleming, and P. Nawroth, "Purification and characterization of the soluble form of the receptor for advanced glycation end-products (sRAGE): a novel fast, economical and convenient method," Experimental and Clinical Endocrinology \& Diabetes, vol. 126, no. 03, pp. 141-147, 2018.

[132] P. S. Yang, T. H. Kim, J. S. Uhm et al., "High plasma level of soluble RAGE is independently associated with a low recurrence of atrial fibrillation after catheter ablation in diabetic patient," Europace, vol. 18, no. 11, pp. 1711-1718, 2016.
[133] C. H. Ha, S. Kim, J. Chung et al., "Inhibitory effect of soluble RAGE in disturbed flow-induced atherogenesis," International Journal of Molecular Medicine, vol. 32, no. 2, pp. 373-380, 2013.

[134] D. Lee, K. H. Lee, H. Park et al., "The effect of soluble RAGE on inhibition of angiotensin II-mediated atherosclerosis in apolipoprotein E deficient mice," PLoS One, vol. 8, no. 8, article e69669, 2013.

[135] J. T. Bukrinski, P. Sonderby, F. Antunes et al., "Glucagon-like peptide 1 conjugated to recombinant human serum albumin variants with modified neonatal $\mathrm{Fc}$ receptor binding properties. Impact on molecular structure and half-life," Biochemistry, vol. 56, no. 36, pp. 4860-4870, 2017.

[136] J. B. Green, M. A. Bethel, P. W. Armstrong et al., "Effect of sitagliptin on cardiovascular outcomes in type 2 diabetes," The New England Journal of Medicine, vol. 373, no. 3, pp. 232-242, 2015.

[137] J. F. E. Mann, V. Fonseca, O. Mosenzon et al., "Effects of liraglutide versus placebo on cardiovascular events in patients with type 2 diabetes mellitus and chronic kidney disease," Circulation, vol. 138, no. 25, pp. 2908-2918, 2018.

[138] S. Verma, N. R. Poulter, D. L. Bhatt et al., "Effects of liraglutide on cardiovascular outcomes in patients with type 2 diabetes mellitus with or without history of myocardial infarction or stroke," Circulation, vol. 138, no. 25, pp. 28842894, 2018.

[139] B. Zinman, C. Wanner, J. M. Lachin et al., "Empagliflozin, cardiovascular outcomes, and mortality in type 2 diabetes," The New England Journal of Medicine, vol. 373, no. 22, pp. 2117-2128, 2015.

[140] M. Abdul-Ghani, S. Del Prato, R. Chilton, and R. A. DeFronzo, "SGLT2 inhibitors and cardiovascular risk: lessons learned from the EMPA-REG OUTCOME study," Diabetes Care, vol. 39, no. 5, pp. 717-725, 2016.

[141] M. J. Levine, "Empagliflozin for type 2 diabetes mellitus: an overview of phase 3 clinical trials," Current Diabetes Reviews, vol. 13, no. 4, pp. 405-423, 2017.

[142] H. Kusaka, N. Koibuchi, Y. Hasegawa, H. Ogawa, and S. KimMitsuyama, "Empagliflozin lessened cardiac injury and reduced visceral adipocyte hypertrophy in prediabetic rats with metabolic syndrome," Cardiovascular Diabetology, vol. 15 , no. 1, p. 157, 2016.

[143] S. Suissa, "Mortality reduction in EMPA-REG OUTCOME trial: beyond the antidiabetes effect," Diabetes Care, vol. 41, no. 2, pp. 219-223, 2018. 


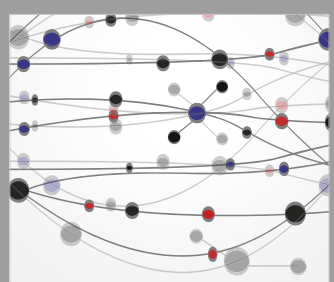

The Scientific World Journal
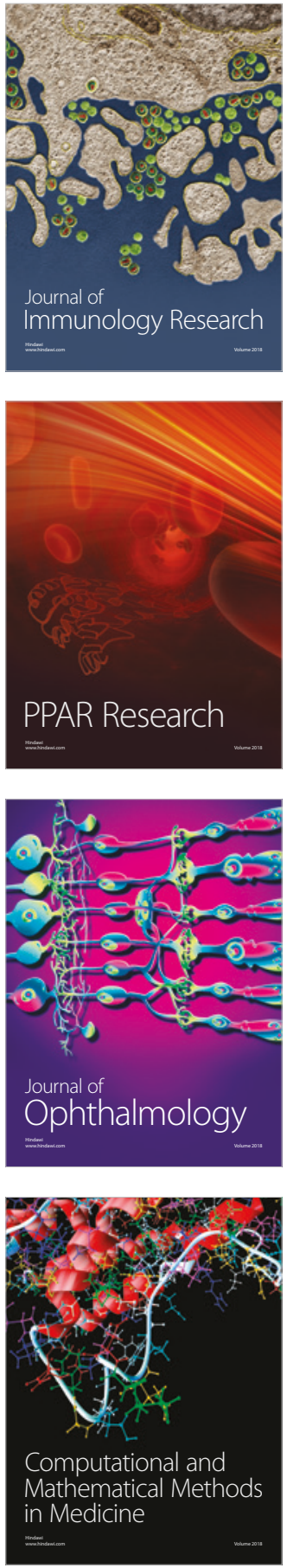

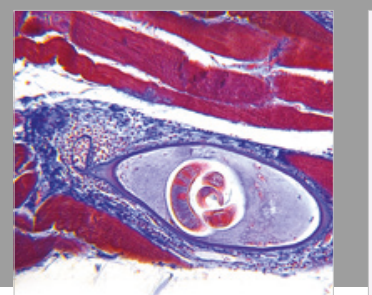

Gastroenterology Research and Practice

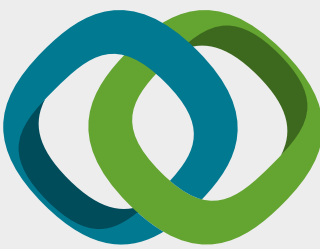

\section{Hindawi}

Submit your manuscripts at

www.hindawi.com
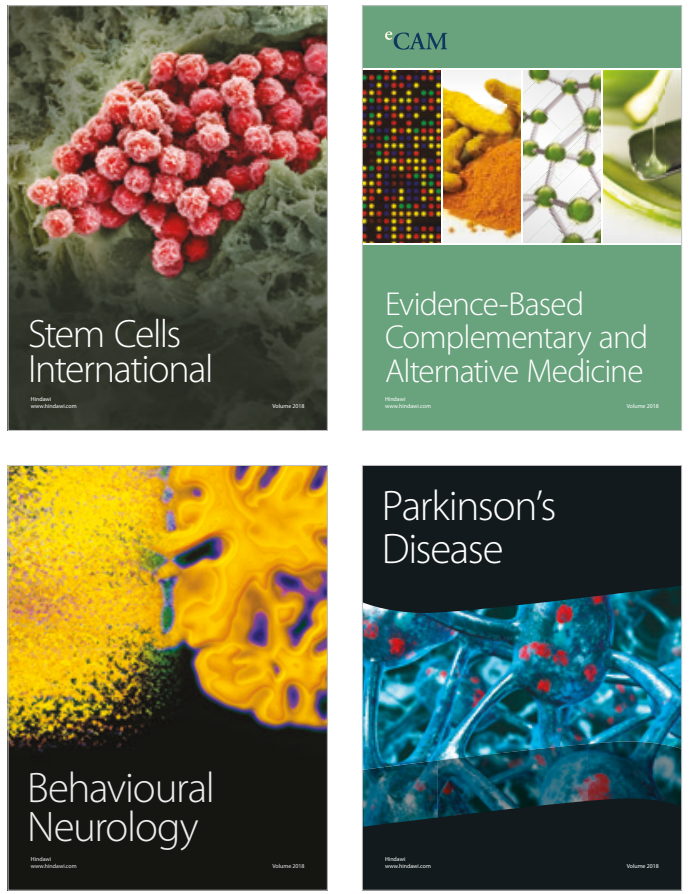

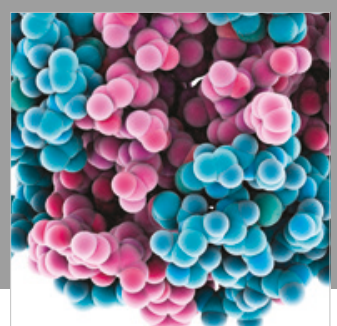

ournal of

Diabetes Research

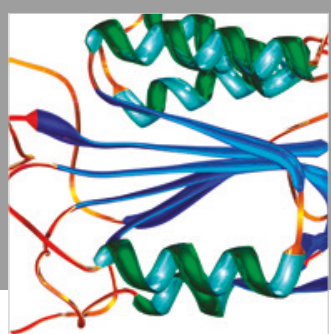

Disease Markers
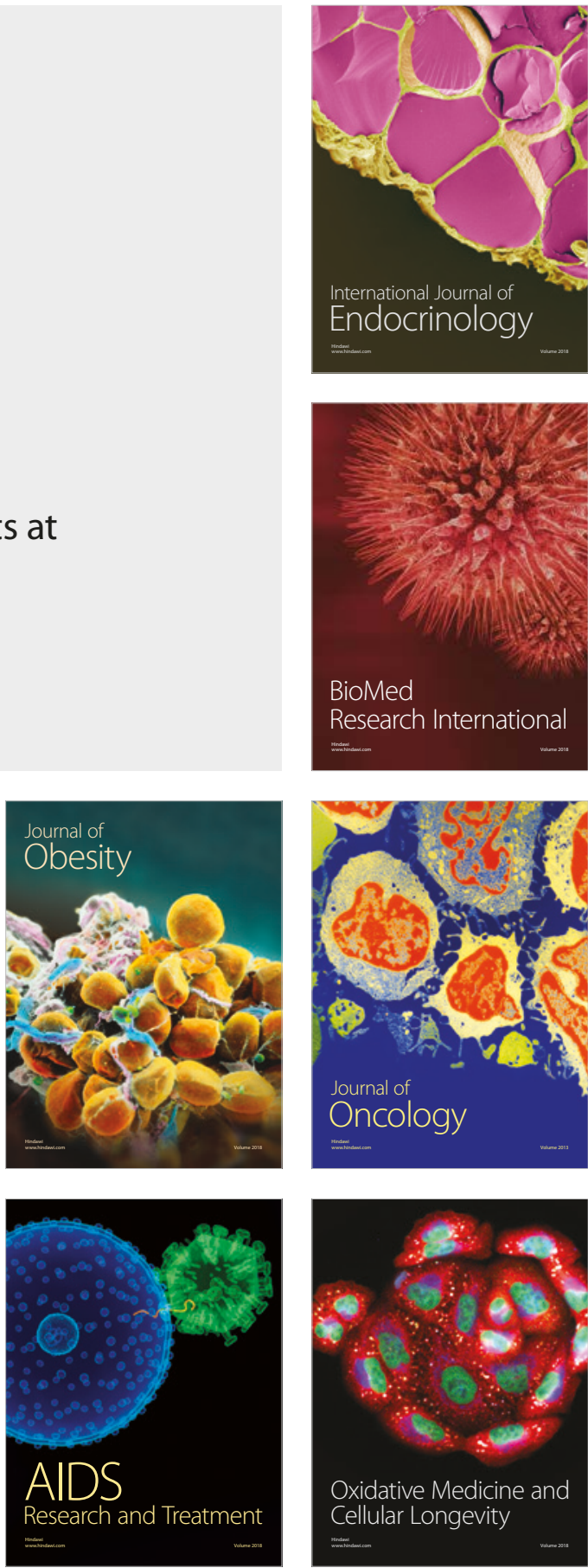